\title{
Fuel Cell Connection Inverters used for Unbalance Compensation in Low Voltage Distribution Systems
}

\author{
H. Beltran, N. Aparicio, E. Belenguer, C. Cervelló García \\ Department of Engineering of Industrial Systems and Design \\ Universitat Jaume I de Castelló \\ Campus de Riu Sec, E-12071 Castelló de la Plana (Spain) \\ Phone: +34 964 728178, Fax: +34 964728170 , \\ e-mail: hbeltran@esid.uji.es, aparicio@esid.uji.es, efbeleng@esid.uji.es, cervello@esid.uji.es
}

\begin{abstract}
The aim of this paper is to evaluate the benefits that can be achieved by operating the connection inverters of the distributed energy resources as active power filters in LV distribution networks. The use of the future fuel cell inverters to compensate zero sequence currents, arising from unbalances among phases, can improve the efficiency of the distribution networks by means of reducing the total amount of losses. A common unbalanced load connected to a LV feeder where a FC inverter is present has been simulated. The reductions in the distribution power losses and compensation of zero sequence currents have been analyzed.
\end{abstract}

\section{Key words}

Active power filters, fuel cells, power quality, unbalances compensation, distributed generation.

\section{Introduction}

Due to the increase in electric consumption, the blackouts recently experienced around Europe and in the USA, and all the environmental concerns such us the global warming, the imperfection of the electric power system (EPS) has become a fact. As our impressive and successful modern grids were evolving, expectations that they could and should be close to perfect led to a system of critically interdependent services vulnerable to grid failure. Heightened security concerns and large penetration of electronics into lots of aspects in everyday life are deepening this vulnerability.

While dependence on the grid has intensified, smaller generation units using a mix of technologies usually collectively called as distributed energy resources (DER) [1], have emerged as increasingly competitive with large remote centralized generation plants. Some of these sources generate power directly, while others involve onsite energy conversion and storage. These technologies are more and more popular and they will present in coming days a high penetration rate within LV distribution systems.
The introduction of new distributed generators (DGs) should not be faced as a handicap but an opportunity to reinforce the whole EPS [2]. It has to be stressed that most of the DER are connected to the utility mains by means of power converters which can be programmed in order to perform a wide range of services. In this way, some of the main points which should and could be improved are: (1) providing higher power quality and reliability (PQR), so that quality provided better matches quality needed; (2) hardening socio-technical systems to an inevitably imperfect grid; (3) reducing losses in the distribution network (by means of reactive power and unbalances compensation), and (4) providing power sources locally to sensitive loads. This last aspect seems to point out the main goal of the system in the future trends. In this way, the evolution of the EPS is focused towards an electric system formed by the union of multiple independent small grids with capability to function apart from the main system. These small grid units have already been named as microgrids. The main advantages of a microgrid can be summarized as:

a) A microgrid can provide an efficient way to integrate DER and loads for taking full advantage of them (including CHP).

b) It should be a "grid-friendly" entity and does not give undesirable influences to the connecting distribution grid. That means the operation policy of the distribution network does not have to be modified.

c) A microgrid can achieve a flexible way for distributed energy resources to connect and disconnect as they like, which is called as "plug-and-play" feature.

d) And finally, microgrids can independently operate without connecting to the upper distribution grid when a fault occurs (islanding mode).

Hence, connection inverters of the different renewable energy resources will have to be adapted to this new EPS structure philosophy. When the microgrid will work in islanded mode, the power converters will be in charge of maintaining the voltage and frequency levels within a narrow range, so that the reconnection with the main EPS 
can be done without further problems. Besides, these converters will have to perform as active power filters (APF) in order to supply the reactive, non linear and unbalance currents demanded by the local loads existing in the microgrid. Nowadays, most of the connection inverters installed in PV installations and those developed for fuel cells (FC), and the rest of DER, are designed in order to produce the maximum possible active power from the energy generated by the renewable energy source. It is clear that this configuration will have to be modified.

Based on the microgrid philosophy where DG converters will have to incorporate lots of control and regulation functions, the main objective of this paper is to analyze the capability of a fuel cell (FC) connection inverter to inject zero sequence currents. That will be done in order to compensate the unbalances existing at the point of common connection (PCC), which are introduced by unbalanced or one phase loads connected to the EPS. This would be one of the first ancillary functions to be performed by these power converters when the EPS will remain connected, that is, to help obtaining a steady state sinusoidal balanced three phase current system flowing out from the MV/LV distribution transformer. This will improve the efficiency of the LV feeder reducing losses in the conductors.

The paper pretends to obtain a simulation model integrating all the components in the proposed system (Transformer, LV feeder, connection inverter and fuel cell generator). The whole model taken into consideration can be observed in Fig. 1. For that purpose, a LV feeder with real parameters and all the rest of components have been simulated using Matlab/Simulink/SimPowerSystem library. This paper tries to summarize the different converters topologies that can be used in order to compensate zero sequence currents in three phase fourwire systems too. And finally, some results on the efficiency improvement are introduced and analyzed.

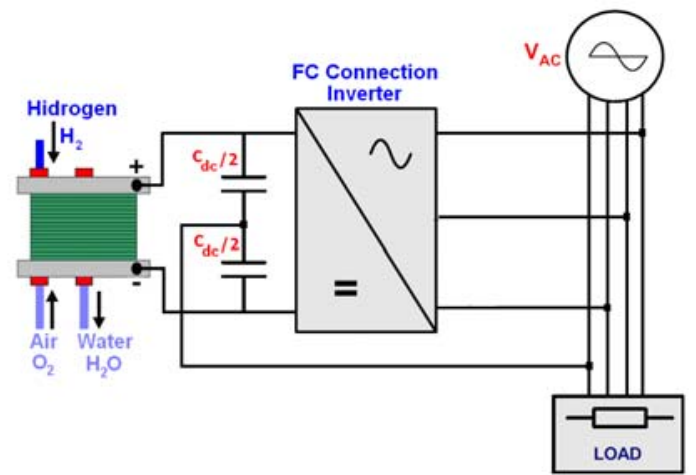

Fig. 1. FC system connected to a LV network.

\section{The Fuel Cell}

\section{A. Description of a Fuel Cell}

The type of FC used in our research is the high temperature proton-exchange membrane (HTPEM) fuel cell. This kind of FC is quite developed and seems to be the first hydrogen technology to be used for massive integration into the EPS. Apart from that, the range of power they produce is from several watts to some tens of kilowatts. This range fits perfectly with the LV distribution network and that is way according to future trends they will be probably used locally in many places by individual consumers.

The behavior of these FCs can be described as follows: at the anode of the fuel cell, the hydrogen gas oxidizes releasing electrons and creating $H^{+}$ions (or protons).

$$
2 \mathrm{H}_{2} \rightarrow 4 \mathrm{H}^{+}+4 e^{-}
$$

During this reaction, energy is released. On the other hand at the cathode, oxygen reacts with electrons taken from the electrode (reduction), and $H^{+}$ions from the electrolyte form water which is a waste product.

$$
\mathrm{O}_{2}+4 e^{-}+4 \mathrm{H}^{+} \rightarrow 2 \mathrm{H}_{2} \mathrm{O}
$$

In the aim to achieve optimal working conditions, proper air flow as well humidification of the gases must be ensured. The overall reaction taking place at the FC can be summarized as:

$$
\mathrm{O}_{2}+2 \mathrm{H}_{2} \rightarrow 2 \mathrm{H}_{2} \mathrm{O}+\text { heat }+ \text { electricity }
$$

Four major irreversibilities can be highlighted in FC [6].

- Activation losses. These are caused by the slowness of the reactions taking place on the surface of the electrodes. A proportion of the voltage generated is lost driving the chemical reaction that transfers the electrons from one electrode to other.

- Fuel crossover and internal current losses. This energy loss results from the waste of the fuel passing through the electrolyte. The fuel loss and its effect are usually not very important.

- Ohmic losses. This voltage drop is the straightforward resistance to the flow of electrons through the materials of the electrodes and the various interconnections.

- Mass transport or concentration losses. These result from the change in concentration of the reactants at the surface of the electrodes as the fuel is used. Because the reduction in concentration is the result of a failure to transport sufficient reactant to the electrode surface, this type of loss is also called "mass transport" loss.

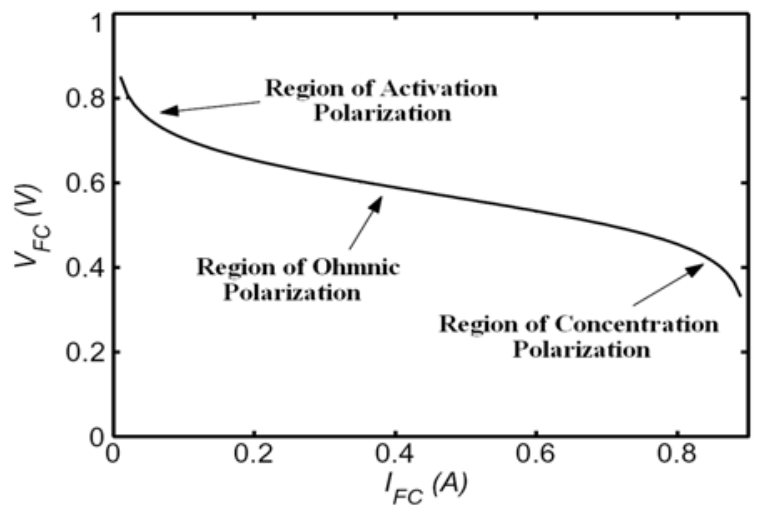

Fig. 2. PEM Fuel Cell V-I characteristic. 
The most important among them are due to the activation and ohmic losses [3]-[6]; at high temperatures the activation losses become less significant than the ohmic ones though. The PEM FC voltage-current characteristic resulting from all of this can be observed in Fig. 2 .

\section{B. Equivalent model of a Fuel Cell}

Taking into account the parameters and characteristics presented in the previous section, the steady state FC voltage, $\mathrm{V}_{\mathrm{FC}}$, is calculated using the following equation:

$$
V_{F C}=E_{\text {rev }}-\eta_{\text {act }}-\eta_{\text {ohmnic }}-\eta_{l}
$$

Where $E_{\text {rev }}$ is the reversible voltage or internal potential of the $\mathrm{FC}$, and the other variables are the irreversible loss voltages, or overpotentials:

- $\eta_{a c t}=$ The voltage loss produced by the activation polarization (activation overpotential)

- $\eta_{\text {ohmnic }}=$ The voltage drop related to the ohmic polarization (ohmic overpotential).

- $\eta_{l}=$ The drop introduced by the concentration polarization (concentration overpotential).

Many attempts have been performed to try to develop and simplify a mathematical model defining the behavior of a PEMFC [7]-[18]. An accurate model can be obtained developing equation (4) and substituting the value of the different overpotentials. The result is equation (5):

$$
\begin{aligned}
V_{F C}=E_{\text {rev }}-\frac{2.3 R T}{\alpha n F} \ln ( & \left.\frac{I_{F C}}{I_{0}}\right)- \\
& \quad-R^{\text {int }} I_{F C}-\frac{R T}{n F} \ln \left(1-\frac{I_{F C}}{I_{l}}\right)
\end{aligned}
$$

Where the different parameters are:

- $R=$ Universal gas constant $(8.31451 \mathrm{~J} /(\mathrm{mol} \cdot \mathrm{K}))$

- $F=$ Faraday's constant (96485Coulomb/mol)

- $T=$ Stack temperature.

- $\alpha=$ Transfer coefficient.

- $n=$ Number of electrons involved in the reaction.

- $R^{\text {int }}=$ Sum of electric and protonic resistance.

- $I_{F C}=$ Fuel Cell current.

- $I_{0}=$ Exchange current.

- $I_{l}=$ Limiting current of the FC.

All this mathematical equation can be represented by the equivalent electric circuit shown in Fig. 3, which fits quite precisely with Dicks-Larminie's model [].

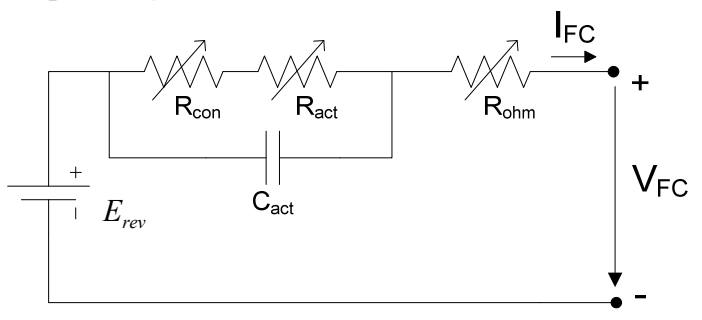

Fig. 3. FC equivalent electric circuit.
The circuit depicted in Fig. 3. is the one implemented in Matlab/Simulink in order to perform the DG integration simulation analysis introduced in this paper.

\section{DC/AC inverter topologies}

Traditionally, based on Akagi's Instantaneous Power Theory published in 1984 [19], Three-Leg Full Bridge (TLFB) inverters have been used as APF in various applications.Nevertheless, this configuration does not allow the inverter to inject zero sequence currents into the EPS, being not useful for three phase unbalanced loads with neutral compensation. For LV distribution networks with presence of the neutral wire, other inverter configurations should be employed to allow zero sequence current injections and the corresponding unbalance compensation [20]-[23]. Three main topologies can be highlighted:

- The first one is known as capacitor midpoint type or Three-Leg Split Capacitor (TLSC). Used for small rating applications. Since the entire neutral current flows through dc-bus capacitors it must have large values. It can be observed in Fig. 4.

- The second topology, known as the four-pole switch type or Four-Leg Full Bridge (FLFB), in which the fourth pole is used to stabilize the neutral of the APF, shown in Fig. 5.

- Finally, the Three-Bridge Four-Wire (TBFW) configu-ration. It is quite common and allows the proper voltage matching for solid-state devices and enhances the reliability of the APF system. It is currently used for high power systems, in Fig.6.

\section{A. The Three-Leg Split Capacitor Converter}

The main advantage of the three-leg split-capacitor configuration (TLSC) is its control simplicity. Due to the fact that the load neutral is connected to the midpoint of the dc bus, all three legs work independently. In this way, the output voltage for each leg is easy to control since it depends only upon its switches state. In fact, this is the most commonly used configuration for low and medium voltage applications, up to $120 \mathrm{~A}$ compensating currents per phase in LV networks. On the other hand, the TLSC topology has some limitations. First of them represents the fact that when no zero sequence is being injected by the inverter into the network (just positive and negative sequence) not all the DC Bus voltage can be profited. This supposes a worse behaviour than the TLFB for this situation.



Fig. 4. Three-Leg Split Capacitor (TLSC) Active Filter 
A second limitation is that the maximum zero sequence voltage amplitude that can be generated at a given moment is dependant on the positive and negative sequence generated in that moment. This is due to the fact that the three compensation components have to be generated by all the three legs of the inverter.

Apart from those two limitations, the main problem arising with this kind of configuration is related to the need of all the zero sequence compensating currents injected by the three phases to flow back through the node 0 , Fig. 5. The injection of the zero sequence currents on this node comprehends the voltage unbalance of the two capacitors forming the DC Bus.

Thus, the three legs do not work symmetrically and their output voltage becomes a function of the switch, upper or lower, being on. This lack in equilibrium makes the control of the inverter harder, since the average output voltage level is not any longer proportional to the duty time of the leg. More complex control algorithms have to be implemented in order to take into account these handicaps of the system.

\section{B. The Four-Leg Full Bridge Converter}

When higher zero sequence currents have to be compensated, the four-leg full-bridge configuration (FLFB) has better behaviour than the TLSC. This topology, comprehends the three legs corresponding to the phases and dedicated to inject positive and negative sequence currents, while the unbalance compensation by means of zero sequence voltage generation is performed by the fourth leg. Moreover, the three initial legs could contribute to the zero sequence generation, as in the TLSC topology, in order to fit high demands of zero sequence currents.

The main advantage of the FLFB configuration is its capability to profit all the DC bus voltage to generate the positive and negative sequence voltages, as for the case of the TLFB, while generating high zero sequence voltage levels. On the other hand, the vector control modulation algorithms developed for this kind of inverters turn to be very complex requiring powerful and expensive control hardware systems which do not count with a large bibliography until now.



Fig. 5. Four-Leg Full Bridge (FLFB) Active Filter

\section{The Three-Bridge Four Wire Converter}

Finally, for high power unbalanced systems requiring zero sequence current components compensation, the most commonly employed topology is the three-bridge four-wire converter (TBFW). This inverter works in a similar way to the FLFB but presents some really interesting advantages for high power applications.

The first advantage is that, while in the FLFB most of the zero sequence current had to flow though the fourth leg, with the corresponding need of powerful switches in case of high compensation demands, in the TBFW, thanks to the isolation transformers, that forth leg of the FLFB can be considered to be split into other three legs corresponding to three single phase independent inverters. That represents a higher current injection capacity. Apart from that, since the maximum output voltage for each of the three one-phase inverters correspond to the DC Bus voltage, this voltage level can be lower than for the other topologies. Besides, using appropriate modulation techniques three level voltage outputs can be obtained, allowing in this way a reduction in the switching frequency as well as the ripple in the injected current.

The last interesting point of the TBFW is that the control of these single phase inverters is simple and well known, increasing the reliability in high power applications. The main limitation of these inverters is their cost.

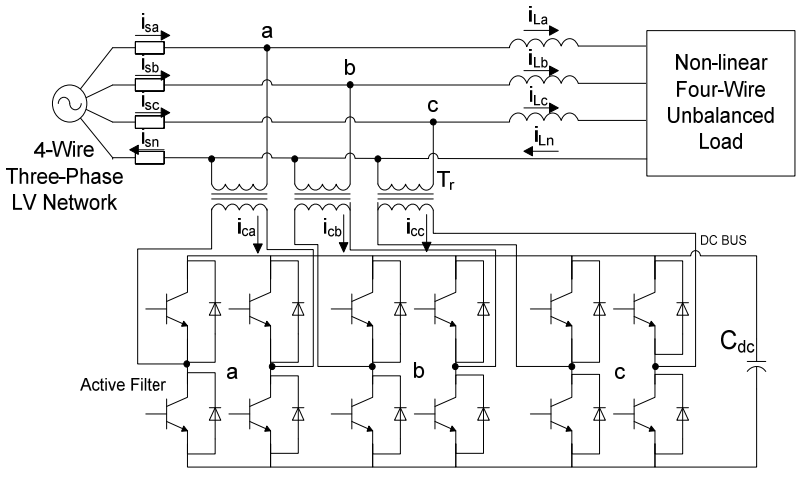

Fig. 6. Three-Bridge Four-Wire (TBFW) Active Filter

\section{FC integrated simulated system}

Two different studies have been performed and are presented for comparison on this paper: the first one analyzes the LV network distribution losses without any compensation, and then a second analysis studies the reduction of losses in the same network when the compensation offered by the FC connection inverters is introduced.

For the first case, a standard example of a MV/LV real transformer with one LV feeder supplying energy to unbalanced loads has been modelled. The scheme of the system can be observed in Fig.7. The three unbalanced loads included in the model correspond to each of the three floors in a residential building which comprehends 
ten apartments per floor. Some reference unbalance levels have been measured previously in real MV/LV substations in order to model these unbalanced loads properly.

The feeder has been split into 4 different LV cable sections: A1 from the distribution transformer to the connection of the building (measuring $100 \mathrm{~m}$ ), A2 from the entrance to the building to the first floor connexion point (measuring 20m), A2 from the first to the second floor connection point (measuring $10 \mathrm{~m}$ ) and finally A3 from the second to the third floor connection point (10m).

The values established for the different elements in the model are obtained from the characteristic parameters of the real standard elements used by Spanish utilities. In this way, the electrical conductor considered for the different line sections is the standard $240 \mathrm{~mm}^{2}$ aluminium conductor for phase wires and a $120 \mathrm{~mm}^{2}$ aluminium conductor for the neutral one. Depending mainly on the material, cross section and length, the values for the four line sections together with $\mathrm{LV}$ distribution transformer impedance $\left(\mathrm{S}_{\mathrm{N}}=630 \mathrm{kVA}, 20 / 0.4 \mathrm{kV}\right)$ are shown in table I.
TABLE I: SYSTEM IMPEDANCES

\begin{tabular}{|c|c|c|c|c|c|}
\hline & Transf & $\begin{array}{c}\text { A1 }(\mathrm{ph} / \\
\text { neutral })\end{array}$ & $\begin{array}{c}\text { A2 }(\mathrm{ph} / \\
\text { neutral })\end{array}$ & $\begin{array}{c}\text { A3 }(\mathrm{ph} / \\
\text { neutral })\end{array}$ & $\begin{array}{c}\text { A4 }(\mathrm{ph} / \\
\text { neutral })\end{array}$ \\
\hline $\mathrm{R}(\mathrm{m} \Omega)$ & 2.54 & $12 / 24$ & $2.4 / 4.8$ & $1.2 / 2.4$ & $1.2 / 2.4$ \\
\hline $\mathrm{X}(\mathrm{m} \Omega)$ & 10 & $3 / 0$ & $0.6 / 0$ & $0.3 / 0$ & $0.3 / 0$ \\
\hline
\end{tabular}

For the second case, the same system has been simulated connecting a FC inverter to each of the connection points of the scheme. Each of the converters will transfer the power proceeding from the FC owned by each of the ten neighbours in the same floor. This represents a future scenario in which every family will have a FC stack at home. Taking into account that the simulated FCs are $1.2 \mathrm{~kW}$ HTPEM, the three inverters have a rated power of $12.5 \mathrm{~kW}$. So the maximum power to be used for unbalanced compensation when no active power is demanded is $37.5 \mathrm{~kW}$. A TLSC topology converter has been used which is the most appropriate configuration for this range of power.

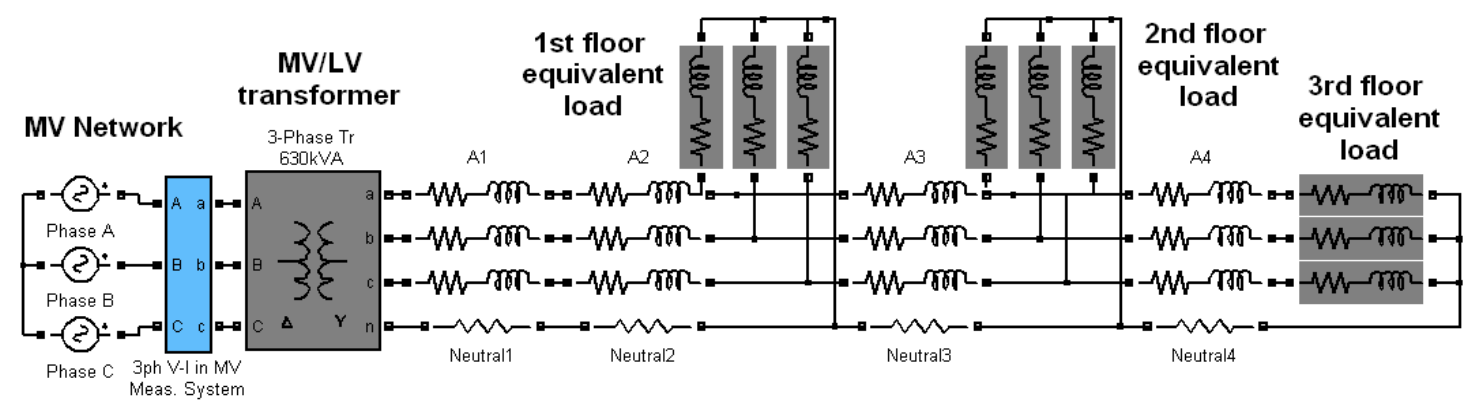

Fig. 7. MV/LV distribution network analyzed.



Fig. 8. FC system integrated to the distribution network. 
By injecting compensation currents at three different points of the feeder, the losses and values of currents flowing along the four LV sections can be studied. The layout of the whole system can be observed in Fig. 8.

The different parameters implemented in the converters are $\mathrm{C}_{\mathrm{DC} \text { bus }}=3300 \mu \mathrm{F}$ for the capacitors in the dc bus and $\mathrm{L}_{\mathrm{CW}}=2.2 \mathrm{mH}$ for the $\mathrm{L}$ connection winding filter. The Fuel Cell Blocks comprehend a DC/DC converter block which increases the dc voltage from $\mathrm{V}_{\mathrm{FC}}$ to the minimum dc voltage allowing the inverter to inject current into the network, around $750 \mathrm{~V}$. This FC block comprehends too the HTPEM model which implements the different equations defining the $\mathrm{FC}$ behaviour.

Finally, the control system driving the different inverters to inject active power and produce the compensation are shown in Fig. 8 as "Control Blocks". They comprehend: the zero crossing detection algorithm, the zero sequence current compensation algorithm, the $\mathrm{dc}$ bus control algorithm (which drives the DC/DC duty cycle fixing the FC system to work approximately at its MPP) and the current control block which is implemented in this case as a hysteretic band control.

\section{Simulation results}

Results and comparison of losses (for balanced load situation and unbalanced load situation, with and without compensation) have been obtained with Matlab for the two cases under study. The first case considered is when the power demand in the building is high, during evening hours, and the degree of unbalance is not very important. And the second case taken into account corresponds to the midday hours when not much energy is required but the system is highly unbalanced.

TABLE II: DEMANDS PER PHASE AND FLOOR (IN KW)

\begin{tabular}{|c|c|c|c|}
\hline & $\begin{array}{c}\text { Demand Floor1 } \\
\text { Phases A/B/C }\end{array}$ & $\begin{array}{c}\text { Demand Floor2 } \\
\text { Phases A/B/C }\end{array}$ & $\begin{array}{c}\text { Demand Floor 3 } \\
\text { Phases A/B/C }\end{array}$ \\
\hline Case 1 & $8 / 10 / 11$ & $9 / 8 / 12$ & $12 / 14 / 15$ \\
\hline Case 2 & $6 / 2 / 1$ & $5 / 2 / 2$ & $4 / 3 / 8$ \\
\hline
\end{tabular}

In both cases, two strategies could be considered: using all the available power in the converter to inject active power and reduce in this way demand form the EPS, or on the other hand using all the converter power to reduce zero sequence unbalances. We propose using the second one injecting active power when possible, that is, when converter power is higher than that required to compensate unbalances.

Currents along the different neutrals wires and the voltages at the DC buses of the inverters have been considered in both cases. For the dc voltage, both capacitors forming the bus have been monitored to study the unbalance in this bus. The connection of the inverters is produced at $0.05 \mathrm{~ms}$ when they start injecting active power. At $0.1 \mathrm{~s}$ the first floor inverter is turned on to compensate unbalances. And finally, at $0.15 \mathrm{~s}$ the other two inverters launch their compensation algorithm. The effects introduced over the neutral currents by them for the case 1 of the study can be observed in Fig. 9.

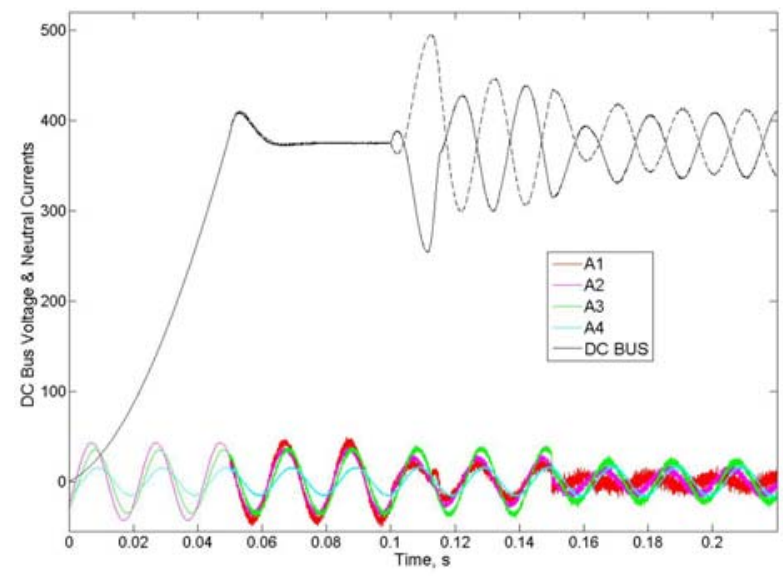

Fig. 9. Power flow in the transformer, case 1.

The neutral current at section A1 is reduced to a value close to zero when all the converters are compensating unbalances (from $0.15 \mathrm{~s}$ on). Previously and from $\mathrm{t}=0.1 \mathrm{~s}$, neutral currents at $\mathrm{A} 1$ and $\mathrm{A} 2$ sections where reduced due to the compensation introduced by the inverter at the first floor. Its dc bus voltages can be appreciated in the same figure showing the great unbalance appearing among capacitors.

\section{A. Case 1-High consumption (Evening hours)}

This first case considers a total load demand in the building of $99 \mathrm{~kW}$. First, results with all the phases balanced $(33 \mathrm{~kW}$ per phase) and the floors equally charged are obtained. Then, the same level of demand is simulated but with the phases unbalanced as specified previously. Table III reflects the values of the losses (in W) for the different LV sections as well as for the distribution transformer. The overall amount of losses in the system for the 4 situations taken into consideration are there summarized.

TABLE III: LOSSES OBTAINED FOR CASE 1(IN W)

\begin{tabular}{|c|c|c|c|c|c|c|}
\hline & $\begin{array}{c}\text { Losses } \\
\text { Transf. }\end{array}$ & $\begin{array}{c}\mathrm{A} 1 \\
(\mathrm{ph} / \mathrm{n})\end{array}$ & $\begin{array}{c}\mathrm{A} 2 \\
(\mathrm{ph} / \mathrm{n})\end{array}$ & $\begin{array}{c}\mathrm{A} 3 \\
(\mathrm{ph} / \mathrm{n})\end{array}$ & $\begin{array}{c}\mathrm{A} 4 \\
(\mathrm{ph} / \mathrm{n})\end{array}$ & $\begin{array}{c}\text { Total } \\
\text { losses }\end{array}$ \\
\hline $\begin{array}{c}\text { Balanced } \\
\text { load }\end{array}$ & 246.4 & 725.3 & 145.1 & 32.2 & 8.0 & 1157 \\
\hline $\begin{array}{c}\text { Un. Load } \\
\text { /inv. not } \\
\text { connected }\end{array}$ & 249.1 & 750 & 150 & 37.2 & 12.8 & 1199 \\
\hline $\begin{array}{c}\text { Un. Load } \\
\text { /inv. not } \\
\text { compensate }\end{array}$ & 114.1 & 561.2 & 122.8 & 33.2 & 12.8 & 844.1 \\
\hline $\begin{array}{c}\text { Un.Load } \\
\text { /inv. } \\
\text { compensate }\end{array}$ & 115.1 & 436.9 & 105.3 & 30.1 & 12.9 & 700.3 \\
\hline
\end{tabular}

Results on table represent a total reduction from the first to the forth situation of the $39.5 \%$. This value reflects a big percentage of reduction but the absolute value is not 
that important since it only represents $457 \mathrm{~W}$ of difference within a $99 \mathrm{~kW}$ of consume system.

\section{B. Case 2-Low consumption (Midday)}

On the other hand, the second case considers a total load demand in the building of $33 \mathrm{~kW}$. Again, firstly results are obtained with all the phases balanced $(11 \mathrm{~kW}$ per phase) and the floors equally charged. Then, the unbalance introduced in the previous section is simulated with and without unbalance compensation.

In this second, case the power demand from the local load will not consume all the energy produced by the FC inverters when working at rated nominal power. In this way, some power generated by the DGs will be injected back to the utility mains. This produces the reductions in the losses no to be so important in percentage compared with the previous case.

The results of the losses, in $\mathrm{W}$, are presented as for the previous case for the different scenarios in Table IV.

TABLE IV: LOSSES OBTAINED FOR CASE 2(IN W)

\begin{tabular}{|c|c|c|c|c|c|c|}
\hline & $\begin{array}{c}\text { Losses } \\
\text { Transf. }\end{array}$ & $\begin{array}{c}\mathrm{A} 1 \\
(\mathrm{ph} / \mathrm{n})\end{array}$ & $\begin{array}{c}\mathrm{A} 2 \\
(\mathrm{ph} / \mathrm{n})\end{array}$ & $\begin{array}{c}\mathrm{A} 3 \\
(\mathrm{ph} / \mathrm{n})\end{array}$ & $\begin{array}{c}\mathrm{A} 4 \\
(\mathrm{ph} / \mathrm{n})\end{array}$ & $\begin{array}{c}\text { Total } \\
\text { losses }\end{array}$ \\
\hline $\begin{array}{c}\text { Balanced } \\
\text { load }\end{array}$ & 29.6 & 81.5 & 16.3 & 3.6 & 0.9 & 131.8 \\
\hline $\begin{array}{c}\text { Un. Load } \\
\text { /inv. not } \\
\text { connected }\end{array}$ & 29.1 & 109.5 & 21.9 & 5.6 & 2.9 & 169 \\
\hline $\begin{array}{c}\text { Un. Load } \\
\text { /inv. not } \\
\text { compensate }\end{array}$ & 14.4 & 69.6 & 14.2 & 4.1 & 2.1 & 104.4 \\
\hline $\begin{array}{c}\text { Un.Load } \\
\text { /inv. } \\
\text { compensate }\end{array}$ & 14.2 & 34.8 & 8.9 & 3.2 & 2.9 & 64 \\
\hline
\end{tabular}

In this case, the percentage of reduction is $51 \%$, even bigger than the previous case since the initial unbalance was higher. Hence, quite a great improvement regarding the percentage of distribution losses is obtained in both cases by introducing the FC inverters in parallel with loads, and even further if these converters are to work as APFs. The second case is more remarkable since the initial unbalance is larger, although there are currents flowing back into the EPS and that, being useful as a renewable energy, increases losses in A1 section in our study.

\section{Conclusion}

The results obtained in this paper confirm the possibility of using the FC connection inverters in order to not only inject active currents into the LV distribution system, but also produce zero sequence currents to inject on the different phases improving the efficiency. A more balanced situation is obtained in the system and neutral currents get cancelled. That comprehends a reduction in the overall distribution losses.
Distributed FC systems could implement the proposed function with just a few modifications in the hardware topology of their connection inverters (referred to the first models appearing in the market which are too close to PV ones) and by adding some control algorithms taking into account zero sequence currents consumed by the different loads.

A brief analysis of the main converter topologies used for zero sequence currents cancellation has been introduced.

A Simulink model of FC system and its connection inverter is simulated. The unbalance compensation is analyzed and the improvement in the power quality of the EPS clearly highlighted. The model has been introduced in a LV network composed of a feeder where unbalanced loads are connected.

Results allow the authors concluding that this application can be really interesting for the near future massive penetration of low power distributed generators in LV distribution systems and, should be taken into account in the development of the new FC connection inverters. The cases of countries such as Spain where renewable resources are so important, could allow combinations of the already well known and largely used PV generators and the arising FC technology. This system could take profit of the not constant power generation performance of the PV panels, no production during night hours, to use the extra rated power for phases balancing and zero sequence currents compensation. The injection of power during these hours would be performed by the FC converter which would obtain the energy from the hydrogen stocked along the daytime hours.

\section{Acknowledgement}

This work was supported by the Institut de la Petita i Mitjana Industria de la Generalitat Valenciana (IMPIVA) and the European Union.

\section{References}

[1] T. Ackermann, G. Andersson and L. Soder, "Distributed generation: a definition," Electr. Power Syst. Res., vol. 57, pp. 195-204, 4/20. 2001.

[2] Tran-Quoc T., Andrieu C., Hadjsaid N.: Technical impacts of small distributed generation units on LV networks, IEEE Power Engineering Society General Meeting, 2003, Vol 4.

[3] J. M. Correa, "Influence of the modeling parameters on the simulation accuracy of proton exchange membrane fuel cells," Power Tech Conference Proceedings, 2003 IEEE Bologna, vol. 2, pp. 8 pp. Vol.2, 2003.

[4] A. Forrai, "Fuel-Cell Parameter Estimation and Diagnostics," Energy Conversion, IEEE Transaction on, vol. 20, pp. 668-675, 2005.

[5] P. J. H. Wingelaar, "Dynamic Characteristics of PEM Fuel Cells," Power Electronics Specialists 
Conference, 2005. PESC '05. IEEE 36th, pp. 16351641, 2005.

[6] Caisheng Wang, "Fuel cells and load transients," Power and Energy Magazine, IEEE, vol. 5, pp. 5863, 2007.

[7] S. Pasricha and S. R. Shaw, "A dynamic PEM fuel cell model," Energy Conversion, IEEE Transaction on, vol. 21, pp. 484-490, 2006.

[8] W. Choi, J. W. Howze and P. Enjeti, "Development of an equivalent circuit model of a fuel cell to evaluate the effects of inverter ripple current," Journal of Power Sources, vol. 158, pp. 1324-1332, 8/25. 2006.

[9] S. Jemei, "PEM fuel cell modelization including durability considerations," Industrial Electronics, 2005. ISIE 2005. Proceedings of the IEEE International Symposium on, vol. 2, pp. 933-937 vol. 2, 2005.

[10]D. Georgakis, S. Papathanasiou and S. Manias, "Modeling and control of a small scale gridconnected PEM fuel cell system," in 2005, pp. 16141620.

[11] M. U. Iftikhar, D. Riu, F. Druart, S. Rosini, Y. Bultel and N. Retière, "Dynamic modeling of proton exchange membrane fuel cell using non-integer derivatives," Journal of Power Sources, vol. 160, pp. 1170-1182, 10/6. 2006.

[12] J. H. Lee and T. R. Lalk, "Modeling fuel cell stack systems," Journal of Power Sources, vol. 73, pp. 229-241, 6/15. 1998.

[13] B. H. Dennis, Z. Han, W. Jin, Bo Ping Wang, L. Xu, T. Aapro, A. Ptchelintsev and T. Reinikainen, "Multi-physics simulation strategies with application to fuel cell modeling," in 2006, pp. 1-5.

[14] N. Fouquet, C. Doulet, C. Nouillant, G. DauphinTanguy and B. Ould-Bouamama, "Model based PEM fuel cell state-of-health monitoring via ac impedance measurements," Journal of Power Sources, vol. 159, pp. 905-913, 9/22. 2006.
[15] Lu-Ying Chiu, "An improved small-signal model of the dynamic behavior of PEM fuel cells," Industry Applications, IEEE Transactions on, vol. 40, pp. 970-977, 2004.

[16] C. Marr and X. Li, "An engineering model of proton exchange membrane fuel cell performance," ARI an International Journal for Physical and Engineering Sciences, vol. 50, pp. 190-200, 05/18. 1998.

[17] J. T. Pukrushpan, "Modeling and control for PEM fuel cell stack system," American Control Conference, 2002. Proceedings of the 2002, vol. 4, pp. 3117-3122 vol.4, 2002.

[18] M. A. A. Younis, N. A. Rahim and S. Mekhilef, "Fuel cell model for three-phase inverter," in 2006, pp. 399-404.

[19] Akagi H., Kanazawa Y., Nabae A.: Instantaneous reactive power compensators comprising switching devices without energy storage components, IEEE Transactions on Industry applications, EPE Journal Vol IA-20 May/June 1984

[20]Fang Zheng Peng and Jih-Sheng Lai, "Generalized instantaneous reactive power theory for three-phase power systems," Instrumentation and Measurement, IEEE Transactions on, vol. 45, pp. 293-297, 1996.

[21] Singh B., Al-Haddad K., Chandra A.: A Review of Active Filters for Power Quality Improvement, IEEE Trans. Ind. Electronics, vol. 46, pp.960-971, Oct 1999.

[22] Quinn C. A., Mohan N.: Active filtering of harmonic currents in three-phase, four-wire systems with three-phase, single-phase nonlinear loads, Proc. IEEE APEC'92, 1992, pp. 829-836.

[23]Lin C. E., Chen C. L., Huang C. H.: Reactive, harmonic current compensation for unbalanced three-phase system, Proc. Int. Conf. High Technology in the Power Industry, 1991, pp. 317321. 